Article

\title{
Optimization of Photopolymerization Process of Dental Composites
}

\author{
Tsanka Dikova $^{1, *} \mathbb{C}$, Jordan Maximov ${ }^{2} \mathbb{C}$, Vladimir Todorov $^{2}$, Georgi Georgiev $^{1}$ and Vladimir Panov ${ }^{1}$ \\ 1 Faculty of Dental Medicine, Medical University of Varna, 84 Tsar Osvoboditel Blvd, 9000 Varna, Bulgaria; \\ Georgi.p.georgiev@mu-varna.bg (G.G.); vladimir.panov@mu-varna.bg (V.P.) \\ 2 Faculty of Mechanical Engineering, Technical University of Gabrovo, 4 Hadji Dimitar Str, \\ 5300 Gabrovo, Bulgaria; maximov@tugab.bg (J.M.); v_p_todorov@abv.bg (V.T.) \\ * Correspondence: tsanka.dikova@mu-varna.bg
}

check for updates

Citation: Dikova, T.; Maximov, J.;

Todorov, V.; Georgiev, G.; Panov, V. Optimization of Photopolymerization Process of Dental Composites. Processes 2021, 9, 779. https:// doi.org/10.3390/pr9050779

Academic Editor: Leszek Adam Dobrzański

Received: 3 April 2021

Accepted: 26 April 2021

Published: 28 April 2021

Publisher's Note: MDPI stays neutral with regard to jurisdictional claims in published maps and institutional affiliations.

Copyright: (C) 2021 by the authors. Licensee MDPI, Basel, Switzerland. This article is an open access article distributed under the terms and conditions of the Creative Commons Attribution (CC BY) license (https:// creativecommons.org/licenses/by/ $4.0 /)$.

\begin{abstract}
The aim of this paper is to perform optimization of photopolymerization process of dental composites in order to obtain maximum hardness. Samples ( $5 \mathrm{~mm}$ diameter; 2, 3 and $4 \mathrm{~mm}$ thickness) were made of Universal Composite (UC), Bulk fill Composite (BC) and Flowable Composite (FC). Light curing of specimens was performed with 600,1000 and $1500 \mathrm{~mW} / \mathrm{cm}^{2}$ light intensity and an irradiation time of 20,40 and $60 \mathrm{~s}$. Vickers microhardness on the top and bottom surfaces of samples was measured. Optimization was carried out via regression analysis using QStatLab software. Photopolymerization process parameters were calculated using a specially designed MatLab software-based algorithm. For all composites, regression models for hardness on top and bottom surfaces of composite layer were established. Layer thickness as well as hardness on top and bottom surfaces of each composite was calculated for 21 curing modes varying with light intensity and irradiation time. It was established that photopolymerization guidelines only of FC manufacturer guarantee the required hardness, while recommended regimes for UC and BC did not satisfy this requirement. Tables, containing recommended light curing regimes, were developed for three composite types, guaranteeing high hardness of composite restoration. They were designed to facilitate work of dentists in dental offices.
\end{abstract}

Keywords: light-cured composites; photopolymerization process; microhardness; optimization; regression analysis

\section{Introduction}

The introduction of light-cured resin-based composites (RBCs) is a revolutionary step in restorative dentistry because it allows clinicians to determine the beginning of the polymerization process. The reasons for their wide application in everyday practice are the increased aesthetic requirements of patients on the one hand, and on the other-the disadvantages of the amalgam such as low aesthetics, galvanic current flow and corrosion, staining of hard dental tissues, soft tissue tattoos, mercury vapor release and others [1].

Dental composites are essentially a mixture of an organic resin matrix, inorganic filler particles, a coupling agent and a photoinitiator system [2,3]. Depending on the size of the filler particles, RBCs are defined as: macrofilled, microfilled, nanofilled and hybrid [4-7]. However, several manufacturers are now incorporating nano-sized particles into their formulations, resulting in the creation of yet another category, the "nanohybrid" composites. Nanofilled composites have silicon-zirconium particles with a size between 0.005 and $0.01 \mu \mathrm{m}$. The small particle size allows good filling of the organic matrix-about $80 \%$. The nanofilled composites present higher mechanical and physical properties to those of microhybrid composites, superior polishability with a gloss comparable to that of the enamel, better wear resistance and transparency [5-8]. Due to their desirable aesthetics, strength and durability, they are increasingly preferred by clinicians as a universal restorative material for both anterior and posterior fillings.

Depending on the viscosity, RBCs are defined as compactable with high viscosity, and flowable with low viscosity. In flowable composites, the percentage of inorganic 
filler is lower and rheological modifiers (substances intended mainly to improve handling properties) have been removed from their composition. Their main advantages are high wettability of the tooth surface, providing penetration into any unevenness; ability to form layers with a minimum thickness, which significantly reduces the inclusion or retention of air; high flexibility, so they are less likely to be displaced in areas with high stress concentration; radiopacity and availability in different colors [9]. The disadvantages include a high level of polymerization shrinkage due to the smaller filler amount and lower mechanical properties. Indications for the use of flowable composites are cervical defects, very small occlusal defects as liners in class I and II cavities [10]. In the last decade, universal highly filled flowable composites have been developed, which allow for the restoration of a wide range of of anterior and posterior defects.

One of the main setbacks of RBCs as a direct restorative material is the application technique sensitivity, meaning that the success of composite restorations largely depends on the operator's skills [11]. The implementation of the adhesive protocol involves many steps and there are enough possibilities for error. In addition, the incremental technique is time consuming and contributes to even more inaccuracies. To simplify the procedure, the bulk fill composites are created.

Bulk fill composites are available in flowable and regular (nonflowable) consistency with the possibility of placing layers up to $5 \mathrm{~mm}$ (compared to $2 \mathrm{~mm}$ for conventional composites), while ensuring an adequate depth of cure. This goal is achieved in various ways, including optimization of the photoinitiator system (new photoinitiators or higher concentration of conventional ones), modification of the fillers (larger size or higher translucency of the particles) or inclusion of various chemicals in the composition [12,13]. The use of bulk fill composites for posterior restorations reduces cusp deflection [14] and polymerization stress [15] while increasing the fracture resistance of the hard tissues and the restoration itself [16]. However, flowable bulk fill composites have lower mechanical properties than non-flowable bulk fill and conventional ones, so they should not be used as a final layer, which is directly exposed to the masticatory forces [17].

The hardness of the materials determines their wear resistance, or their ability to abrade or be abraded from the opposite tooth structures $[18,19]$. The hardness of RBCs is influenced by several factors, the most important of which are the composition of the organic matrix, the type and amount of inorganic fillers and the degree of monomerpolymer conversion. A positive relationship has been found between the increase in hardness and the increase in the degree of conversion. The microhardness tests are most commonly used for indirect evaluation of the depth of cure and the degree of conversion of dental composites [20-22], because a small change in the degree of conversion can lead to a large hardness change [23].

The amount of light energy reaching the surface and the bottom of the composite restoration depends on many variables, such as the light intensity of the light curing unit (LCU), curing time, distance and angulation of the LCU's tip, composition, thickness, color and opacity of the composite. Therefore, the measured hardness at the top surface of the restoration cannot be accepted as an indicator of the hardness at its bottom. Less than $20 \%$ difference between the maximum hardness at the top of the composite and that found at the bottom is suggested as a guideline for adequate curing of the resin composite [24-26]. In addition, a bottom-to-top KHN ratio of $80 \%$ has been reported to correspond to a bottom-to-top degree of conversion ratio of $90 \%$ [24].

Many researchers have investigated the efficiency of different curing modes for successful polymerization of the resin-based composites expressed mainly by their hardness. Zhu S. and Platt J. [27] established that the polymerization mode and the curing tip distance had a significant effect on the hardness of the composites. Aguiar F.H.B. et al. [28] evaluated the influence of light curing modes and curing time on the microhardness of a hybrid composite. It was found that the increase of the light curing time and usage of appropriate LCU could lead to maximum hardness in polymerization of composites in deep cavities. The research of Spajic J. et al. [29] showed that in the light-cured materials, the material 
type had the highest effect on the microhardness, followed by the irradiation time, while the curing mode had the lowest impact. Alkhughairy F.I. [30] investigated the effect of two curing light intensities on the mechanical properties of bulk fill composites. A positive influence of the higher curing light intensity $\left(1200 \mathrm{~mW} / \mathrm{cm}^{2}\right)$ on the microhardness of the bulk fill composites was found.

Despite the daily and routine placement of composite restorations, dentists' level of knowledge about the composite properties and the main factors of the photopolymerization process-light intensity, irradiation time and layer thickness is not high [31,32]. The poor awareness can lead to incorrect curing protocol, which in turn can lead to an incomplete polymerization of the material with all the adverse consequences: reduced hardness and wear resistance, low adhesive bond strength and increased risk of restoration fracture, elution of residual monomers and faster color change. Therefore, there is a need for development of guidance for the curing modes, ensuring effective polymerization of the resin-based composites mostly used in dental practice.

In evaluation the influence of different curing modes on the polymerization process and the composites properties, most of the researchers use different methods of the statistical analysis; independent and paired sample $t$-test, one-way and two-way analysis of variance, multiple comparisons with Tukey test, full factorial ANOVA [27,29,30]. However, these methods allow only the influence and significance of the different parameters of polymerization process as well as the correlation between them to be revealed. Using the regression analysis, the optimal parameters of each process, which guarantee maximal properties of the object or material, can be calculated [33-37].

Therefore, the aim of this paper is to use regression analysis and to perform an optimization of the parameters of photopolymerization process in order to obtain maximum hardness of the dental composites. To the best of our knowledge, this kind of engineering approach is applied here for the first time in order to investigate resin-based composites. Universal nanohybrid, bulk fill and flowable light-cured composites are used in the research. Light curing modes for each composite are developed, which can serve as guidance for successful polymerization in the daily work of dentists.

\section{Materials and Methods}

\subsection{Materials and Samples Preparation}

Round samples with diameter of $5 \mathrm{~mm}$ and thickness of 2, 3 and $4 \mathrm{~mm}$ were prepared of three types of light-cured resin-based composites: Universal nanohybrid Composite (UC) Evetric (Ivoclar Vivadent, Lichtenstein, Germany), nanohybrid Bulk fill Composite (BC) for posterior restorations Filtek One Bulk Fill Restorative (3M Oral Care, St. Paul, MN, USA) and universal nanofilled Flowable Composite (FC) G-aenial Universal Flo (GC, Tokyo, Japan), indicated for restorations of all cavity classes. All composites were of A2 shade, but had a different composition and organic matrix/fillers ratio (Table 1).

The samples were prepared in three polyurethane molds with internal dimeter of $5 \mathrm{~mm}$ and thickness of 2,3, and $4 \mathrm{~mm}$. Glass slides and transparent celluloid strips on the top and bottom of the molds were used that guaranteed smooth surfaces and the same dimensions of all samples in the groups. The polymerization was performed with light curing unit Curing Pen (Eighteeth, Changzhou, China) with 600, 1000 and $1500 \mathrm{~mW} / \mathrm{cm}^{2}$ light intensity and irradiation time of 20, 40 and $60 \mathrm{~s}$ [29,31]. LCU's tip was placed parallel and in contact with the glass slide at a distance of $1 \mathrm{~mm}$ from the sample. Three specimens were prepared for each combination of parameters. They were stored in a dry dark container at room temperature for $24 \mathrm{~h}$, after which the hardness measurements were performed. 
Table 1. Composition of the composites used [38-42].

\begin{tabular}{|c|c|c|c|}
\hline \multirow{2}{*}{ Composite } & \multicolumn{3}{|l|}{ Composition } \\
\hline & Component & Amount & Matrix/Filler Ratio, wt $\%$ \\
\hline $\begin{array}{c}\text { UC } \\
\text { Evetric }\end{array}$ & $\begin{array}{c}\text { Matrix: } \\
\text { BIS-GMA (Bisphenol A glycydil dimethacrylate) } \\
\text { UDMA (Urethane dimethacrylate) } \\
\text { Bis-EMA (Bisphenol A polyethethylene glycol dimethacrylate) } \\
\text { Fillers: } \\
\text { Barium glass, Ytterbium Fluoride (YbF3), Mixed oxides and } \\
\text { prepolymers } 40 \mathrm{~nm}-3 \mu \mathrm{m}\end{array}$ & $\begin{array}{c}3-10 \% \\
10-25 \% \\
3-10 \%\end{array}$ & $19-20 / 80-81$ \\
\hline $\begin{array}{l}\text { BC } \\
\text { Filtek One Bulk } \\
\text { Fill Restorative }\end{array}$ & $\begin{array}{c}\text { Matrix: } \\
\text { AUDMA (Aromatic Urethane Dimethacrylate) } \\
\text { DDDMA (1,12-Dodecane Dimethycrylate) } \\
\text { UDMA (Urethane dimethacrylate) } \\
\text { Fillers: } \\
\text { Silane Treated Ceramic, Silica, Zirconia and Ytterbium Fluoride }\end{array}$ & $\begin{array}{c}10-20 \% \\
<10 \% \\
1-10 \%\end{array}$ & $23.5 / 76.5$ \\
\hline $\begin{array}{c}\text { FC } \\
\text { G-aenial } \\
\text { Universal Flo }\end{array}$ & $\begin{array}{c}\text { Matrix: } \\
\text { UDMA (Urethane dimethacrylate) } \\
\text { Bis-EMA (Bisphenol A polyethethylene glycol dimethacrylate) } \\
\text { Dimethacrylate component } \\
\text { Fillers: } \\
\text { Silicon dioxide }(16 \mathrm{~nm}) \text {, Strontium glass }(200 \mathrm{~nm}) \text {, pigments }\end{array}$ & $\begin{array}{c}10-20 \% \\
5-10 \% \\
5-10 \%\end{array}$ & $31 / 69$ \\
\hline
\end{tabular}

\subsection{Hardness Measurements}

The Vickers microhardness was investigated by ZHV $\mu-S$ (Zwick/Roell, Ulm-Einsingen, Germany) hardness tester with $50 \mathrm{gr}$ loading for $10 \mathrm{~s}$. Five measurements were performed on the top and bottom surfaces of each specimen and the mean values were recorded.

\subsection{Regression Analysis}

An optimization of the three parameters of the photopolymerization process, light intensity $I$, irradiation time $t$ and layer thickness $d$ was caried out. The aim was to obtain a composite layer with a certain thickness, having maximum microhardness on the top surface (HVmax) and microhardness on the bottom surface, 80\% of HVmax [24-26], in given intensity values and irradiation times, specific for each LCU.

The governing factors, namely intensity $I$, irradiation time $t$ and layer thickness $d$ as well as their levels, are listed in Table 2. The factors, measured in natural physical units, are marked with $\widetilde{x}_{i}$ and have different dimensions. In order to eliminate the experimental plan's dependence from the dimensions, the factors $\widetilde{x}_{i}$ are transformed into a coded form $x_{i}$ through dependence

$$
x_{i}=\left(\widetilde{x}_{i}-\tilde{x}_{i, 0}\right) /\left|\widetilde{x}_{i, \max }-\tilde{x}_{i, 0}\right|
$$

The objective functions are: $Y_{1}, \mathrm{HV}$ with hardness on the top surface of the composite layer and $Y_{2}, \mathrm{HV}$ hardness on the bottom surface. A planned experiment for the three investigated composites was carried out. The experimental design is shown in Table 3.

Regression analyses of the obtained experimental results for each composite were carried out through QStatLab v 6.1 software. For the objective functions $Y_{i}, i=1,2$, polynomials from second order were chosen since the governing factors were changed of three levels [33]:

$$
Y_{k}(\{X\})=a_{0}+\sum_{i=1}^{m} a_{i} x_{i}+\sum_{i=1}^{m-1} \sum_{j=i-1}^{m} a_{i j} x_{i} x_{j}+\sum_{i=1}^{m} a_{i i} x_{i}^{2}, k=1,2,
$$

where $\{X\}=\left[x_{1} x_{2}\right]^{T} \in \Gamma_{x}$ is the vector of the governing factors, $\Gamma_{x}$ is the admissible space of the governing factors and $m$ is their number. 
For each of the composites, regression models were created for the objective functions $Y_{1}$, hardness on the top surface of the composite layer, and $Y_{2}$, hardness on the bottom surface. Using regression models for UC, Evetric optimizations were made in nine variations of the governing factors intensity $\left(x_{1}\right)$ and irradiation time $\left(x_{2}\right)$. As a condition for optimization, for each composite the average value of the microhardness on the top surface obtained in the experiment was accepted, and for the microhardness on the bottom surface $80 \%$ of the microhardness on the top surface.

Table 2. Governing factors and their levels.

\begin{tabular}{|c|c|c|c|c|c|}
\hline \multicolumn{6}{|c|}{ Governing Factors } \\
\hline \multirow[t]{7}{*}{ Natural $\tilde{x}_{i}$} & \multirow[t]{7}{*}{ Coded $x_{i}$} & \multicolumn{4}{|c|}{ Levels of the Factors } \\
\hline & & \multicolumn{4}{|c|}{ Coded } \\
\hline & & \multicolumn{4}{|c|}{ For the first factor } \\
\hline & & -1 & -0.1111 & & 1 \\
\hline & & \multicolumn{4}{|c|}{ For the rest factors } \\
\hline & & -1 & & 0 & 1 \\
\hline & & \multicolumn{4}{|c|}{ Natural } \\
\hline Intensity I $\left[\mathrm{mW} / \mathrm{cm}^{2}\right] \widetilde{x}_{1}$ & $x_{1}$ & 600 & 1000 & & 1500 \\
\hline Time $\mathrm{t}[\mathrm{s}] \tilde{x}_{2}$ & $x_{2}$ & 20 & & 40 & 60 \\
\hline Thickness d [mm] $\widetilde{x}_{3}$ & $x_{3}$ & 2 & & 3 & 4 \\
\hline
\end{tabular}

Table 3. Experimental design.

\begin{tabular}{|c|c|c|c|c|c|c|c|c|c|c|c|c|}
\hline \multirow{4}{*}{ № } & \multirow{2}{*}{\multicolumn{6}{|c|}{$\begin{array}{c}\text { Composite Type } \\
\text { Governing Factors }\end{array}$}} & \multicolumn{2}{|c|}{$\mathrm{UC}$} & \multicolumn{2}{|c|}{ BC } & \multicolumn{2}{|c|}{ FC } \\
\hline & & & & & & & \multirow{3}{*}{$\begin{array}{l}Y_{1} \\
\text { HV } \\
\text { Top }\end{array}$} & \multirow{3}{*}{$\begin{array}{c}Y_{2} \\
\text { HV } \\
\text { Bottom }\end{array}$} & \multirow{3}{*}{$\begin{array}{l}Y_{1} \\
\text { HV } \\
\text { Top }\end{array}$} & \multirow{3}{*}{$\begin{array}{c}Y_{2} \\
\text { HV } \\
\text { Bottom }\end{array}$} & \multirow{3}{*}{$\begin{array}{l}Y_{1} \\
\text { HV } \\
\text { Top }\end{array}$} & \multirow{3}{*}{$\begin{array}{c}Y_{2} \\
\text { HV } \\
\text { Bottom }\end{array}$} \\
\hline & \multicolumn{3}{|c|}{ Coded } & \multicolumn{3}{|c|}{ Natural } & & & & & & \\
\hline & $x_{1}$ & $x_{2}$ & $x_{3}$ & $\mathrm{I}, \mathrm{mW} / \mathrm{cm}^{2}$ & $t, s$ & $\mathrm{~d}, \mathrm{~mm}$ & & & & & & \\
\hline 1 & -1 & -1 & -1 & 600 & 20 & 2 & 42.0 & 33.5 & 59.1 & 55.8 & 42.4 & 37.9 \\
\hline 2 & 1 & -1 & -1 & 1500 & 20 & 2 & 52.4 & 42.9 & 61.7 & 60.2 & 50.0 & 46.3 \\
\hline 3 & -1 & 1 & -1 & 600 & 60 & 2 & 45.9 & 41.1 & 61.8 & 61.1 & 47.5 & 45.5 \\
\hline 4 & 1 & 1 & -1 & 1500 & 60 & 2 & 57.8 & 51.3 & 68.4 & 67.5 & 49.9 & 47.7 \\
\hline 5 & -1 & -1 & 1 & 600 & 20 & 4 & 45.0 & 12.2 & 57.9 & 45.4 & 42.9 & 13.1 \\
\hline 6 & 1 & -1 & 1 & 1500 & 20 & 4 & 58.9 & 26.1 & 61.7 & 55.3 & 45.0 & 27.0 \\
\hline 7 & -1 & 1 & 1 & 600 & 60 & 4 & 49.3 & 32.7 & 60.3 & 57.5 & 45.3 & 31.7 \\
\hline 8 & 1 & 1 & 1 & 1500 & 60 & 4 & 62.7 & 45.0 & 67.2 & 65.3 & 48.1 & 42.6 \\
\hline 9 & -0.1111 & -1 & -1 & 1000 & 20 & 2 & 54.1 & 42.2 & 62.2 & 60.3 & 47.7 & 42.3 \\
\hline 10 & -0.1111 & 1 & 1 & 1000 & 60 & 4 & 56.9 & 35.8 & 65.1 & 61.6 & 45.8 & 37.6 \\
\hline 11 & -1 & 0 & -1 & 600 & 40 & 2 & 42.4 & 38.2 & 63.8 & 60.3 & 45.3 & 43.5 \\
\hline 12 & 1 & 0 & 1 & 1500 & 40 & 4 & 61.7 & 38.4 & 65.3 & 62.5 & 45.5 & 36.5 \\
\hline 13 & -1 & -1 & 0 & 600 & 20 & 3 & 44.3 & 22.2 & 59.2 & 51.8 & 46.1 & 29.9 \\
\hline 14 & 1 & 1 & 0 & 1500 & 60 & 3 & 59.3 & 48.7 & 69.1 & 67.3 & 51.1 & 47.1 \\
\hline
\end{tabular}

\subsection{Calculation of the Parameters of Photopolymerization Process}

The above-mentioned condition for optimization led to incorrect solutions of the equations of regression analysis for some regimes of UC Evetric. These incorrect solutions were referred to the photopolymerization parameters, in which the values of the microhardness on the top surface were less than the acceptable ones. Thus, the difference in the microhardness between the top and bottom surfaces was larger than $20 \%$.

For that reason, a MatLab software-based algorithm was developed to calculate the microhardness on the top and bottom surfaces as well as the layer thickness, which met the requirement for maximum microhardness and 20\% difference. 
The regression model for each composite is used as basis of the algorithm in the newly designed program. If UC Evetric is taken as an example, the microhardness (at top and bottom, respectively) as a function of the governing factors is:

$$
\begin{gathered}
Y_{1}=56.266+6.402 x_{1}+1.5325 x_{2}+2.0025 x_{3}-4.458 x_{1}^{2} \\
Y_{2}=35.936+6.118 x_{1}+6.459 x_{2}-6.991 x_{3}+1.189 x_{1} x_{3}+3.089 x_{2} x_{3} .
\end{gathered}
$$

The following equation expresses the relationship between the two objective functions:

$$
0.8 Y_{1}-Y_{2}=0
$$

The Equation (5) is solved with respect to the thickness $x_{3}$ :

$$
x_{3}=x_{3}\left(x_{1}, x_{2}\right)
$$

or, taking into account (3) and (4):

$$
x_{3}=\frac{-9.0768+0.9964 x_{1}+5.233 x_{2}+3.5664 x_{1}^{2}}{8.593-1.189 x_{1}-3.089 x_{2}} .
$$

In the above expression, the coded values of intensity $\left(x_{1}\right)$ and time $\left(x_{2}\right)$ are replaced, and the thickness (coded values) is calculated. The coded coordinates $x_{1}$ and $x_{2}$ as well as the calculated thickness $x_{3}$ are replaced in the expressions for the objective functions $Y_{1}$ and $Y_{2}$ and the corresponding microhardnesses are calculated. It should be noted that they would be obtained in proportion $1: 0.8$.

The thickness of the sample in physical coordinates is obtained via the transformation:

$$
\widetilde{x}_{3}=\left(\widetilde{x}_{3, \max }-\tilde{x}_{3,0}\right) x_{3}+\widetilde{x}_{3,0}
$$

where $\widetilde{x}_{3}$ is the thickness $(\mathrm{mm}), \widetilde{x}_{3, \max }$ is the maximal thickness $(\mathrm{mm}), \widetilde{x}_{3,0}$ is the average level of the thickness ( $\mathrm{mm})$.

\section{Results}

\subsection{Microhardness}

The mean values of the microhardness measurements on the composite sample top and bottom surfaces are shown in Table 3. BC Filtek One Bulk Fill Restorative is characterized by a highest maximum microhardness of $65+/-4 \mathrm{HV}$, followed by UC Evetric with 56+/ $-4 \mathrm{HV}$, and the lowest microhardness $47+/-4 \mathrm{HV}$ is obtained for FC G-aenial Universal Flo. These values are used as optimization condition in the regression analysis of the investigated composites.

\subsection{Universal nanohybrid composite Evetric}

The regression models for the objective functions $Y_{1}$-hardness on the top surface of the composite layer and $Y_{2}$-hardness on the bottom surface of UC Evetric are shown in Formulas (3) and (4). Using regression models, nine optimizations are conducted for this composite in different combinations of the parameters intensity $\left(x_{1}\right)$ and irradiation time $\left(x_{2}\right)$ and the results are given in Table 4 . In regimes with lower intensity $\left(600 \mathrm{~mW} / \mathrm{cm}^{2}\right.$ and $1000 \mathrm{~mW} / \mathrm{cm}^{2} / 20 \mathrm{~s}$ ) incorrect solutions are obtained, referring to the lower microhardness values or HV difference between the top and bottom surfaces larger than $20 \%$. With the help of the newly designed program, maximum microhardness on the top surface, $80 \%$ microhardness on the bottom surface and the layer thickness (which guarantees it) were calculated for variations of irradiation time and LCU intensity. The results obtained are shown in Table A1 (Appendix A). 
Table 4. Optimal regimes for photopolymerization of UC Evetric obtained by regression analysis.

\begin{tabular}{|c|c|c|c|c|c|c|}
\hline № & $\underset{\mathrm{mW} / \mathrm{cm}^{2}}{\mathrm{I}}$ & $\begin{array}{l}\mathbf{t} \\
\mathbf{s}\end{array}$ & $\underset{\mathrm{mm}}{\mathrm{d}}$ & $\begin{array}{l}\text { HV } \\
\text { Top }\end{array}$ & $\begin{array}{c}\text { HV } \\
\text { Bottom }\end{array}$ & Note \\
\hline 1 & 1500 & 60 & 3.10 & 60.0 & 48.0 & \\
\hline 2 & 1500 & 40 & 3.05 & 58.3 & 41.6 & \\
\hline 3 & 1500 & 20 & 2.35 & 55.3 & 41.6 & Regimes that meet the requirement of max HV $56+/-4$ on the top surface \\
\hline 4 & 1000 & 60 & 2.85 & 57.0 & 43.0 & and $H V$ on the bottom surface $\geq 80 \%$. \\
\hline 5 & 1000 & 40 & 2.15 & 53.9 & 41.6 & \\
\hline 6 & 1000 & 20 & \multicolumn{3}{|c|}{ Incorrect solution } & HV difference between top and bottom surface is larger than $20 \%$. \\
\hline 7 & 600 & 60 & \multicolumn{3}{|c|}{ Incorrect solution } & \\
\hline 8 & 600 & 40 & \multirow{2}{*}{\multicolumn{3}{|c|}{ Incorrect solution }} & $\mathrm{HV}$ values on the top surface are lower than the acceptable $56+/-4$. \\
\hline 9 & 600 & 20 & Incorrect solution & & & \\
\hline
\end{tabular}

The data in Table A1 (Appendix A) can be classified into three groups. The first group includes the curing modes that do not provide the necessary microhardness on the top and bottom surfaces, which is a sign of insufficient polymerization. These are the regimes with an intensity of $600-700 \mathrm{~mW} / \mathrm{cm}^{2}$ for all irradiation times, and an intensity of $800 \mathrm{~mW} / \mathrm{cm}^{2}$ for time 20 and $40 \mathrm{~s}$. The second is the boundary group with two modes: $800 \mathrm{~mW} / \mathrm{cm}^{2} / 60 \mathrm{~s}$ and $1000 \mathrm{~mW} / \mathrm{cm}^{2} / 20 \mathrm{~s}$, which provide hardness close to the lower limit. Taking into account the microhardness increase of the composite over time [43], these regimes can be considered acceptable. The third group includes all modes with intensity $1000 \mathrm{~mW} / \mathrm{cm}^{2}$ for time 40 and $60 \mathrm{~s}$, as well as those over $1000 \mathrm{~mW} / \mathrm{cm}^{2}$. They guarantee maximum microhardness on the top surface, and $80 \%$ HVmax on the bottom surface at the calculated thickness of the composite layer. In irradiating for a maximum of $60 \mathrm{~s}$, the layer thickness at which $80 \% \mathrm{HVmax}$ is achieved on the bottom surface is larger than that recommended by the manufacturer-2 $\mathrm{mm}$ [39]. Our results show that in this case it is possible to work with a layer thickness of up to $2.39 \mathrm{~mm}$ for $1200 \mathrm{~mW} / \mathrm{cm}^{2}, 2.54 \mathrm{~mm}$ for $1300 \mathrm{~mW} / \mathrm{cm}^{2}$ and $3.17 \mathrm{~mm}$ for $1500 \mathrm{~mW} / \mathrm{cm}^{2}$. On the other hand, the manufacturer recommends $2 \mathrm{~mm}$ composite layer to be polymerized for $20 \mathrm{~s}$ with LCU intensities between 500 and $1000 \mathrm{~mW} / \mathrm{cm}^{2}$ and for $10 \mathrm{~s}$ with intensities above $1000 \mathrm{~mW} / \mathrm{cm}^{2}$. The results, obtained by us, disprove these recommendations, as observance of the specified parameters would not lead to satisfactory microhardness of the material.

\subsection{Nanohybrid Bulk Fill Composite Filtek One Bulk Fill Restorative}

For BC Filtek One Bulk Fill Restorative the regression models for the objective functions $Y_{1}$ and $Y_{2}$ are of the following type:

$$
\begin{gathered}
Y_{1}=64.55+2.327 x_{1}+2.256 x_{2}-0.704 x_{3}-1.866 x_{2}^{2}+1.003 x_{1} x_{2}, \\
Y_{2}=59.113+3.596 x_{1}+4.170 x_{2}-2.740 x_{3}+1.162 x_{1} x_{3}+1.397 x_{2} x_{3} .
\end{gathered}
$$

The regression models are used for constitution of Equation (5) in order to obtain the thickness $x_{3}$ :

$$
x_{3}=\frac{7.473+1.7344 x_{1}+2.3652 x_{2}+1.4928 x_{2}^{2}-0.8024 x_{1} x_{2}}{2.1768-1.162 x_{1}-1.397 x_{2}} .
$$

The results obtained are shown in Table A2 (Appendix B). Only at $I=600 \mathrm{~mW} / \mathrm{cm}^{2}$ and $t=20 \mathrm{~s}$ there is a thickness of $3.86 \mathrm{~mm}$ in the range $2-4 \mathrm{~mm}$, where the bottom/top microhardness ratio is equal to 0.8 and the accuracy of the calculated hardness $(56.63 \mathrm{HV}$ on top and $45.30 \mathrm{HV}$ on bottom) is guaranteed. For all other "intensity-time" combinations in the table, the calculated limit thickness is larger than the upper limit of the range $2-4 \mathrm{~mm}$. In this composite, for all combinations in the table (except for the first), the bottom/top microhardness ratio is higher or less than 0.8. For the calculated thicknesses larger than $4 \mathrm{~mm}$, i.e., outside the defined range $2-4 \mathrm{~mm}$, the accuracy of the calculated hardness 
is not guaranteed, as the regression models are valid only for the intervals in which the governing factors are changed.

Figure 1 illustrates the dependences of the microhardness on the top surface $Y_{1}$ and the bottom/top microhardness ratio $Y_{2} / Y_{1}$ as a function of thickness for mode 3 in Table A2 (Appendix B) $\left(\mathrm{I}=600 \mathrm{~mW} / \mathrm{cm}^{2}\right.$ and $\left.\mathrm{t}=60 \mathrm{~s}\right)$. For the first mode in Table A2 (Appendix B) the limit thickness is $3.86 \mathrm{~mm}$, while for all others it is over $4 \mathrm{~mm}$. Taking into account the increase of $Y_{2} / Y_{1}$ with thickness decrease (Figure 1), it can be assumed that for the entire thickness interval (2-4 mm) the bottom/top microhardness ratio should be higher than 0.8 , which satisfies the requirement.

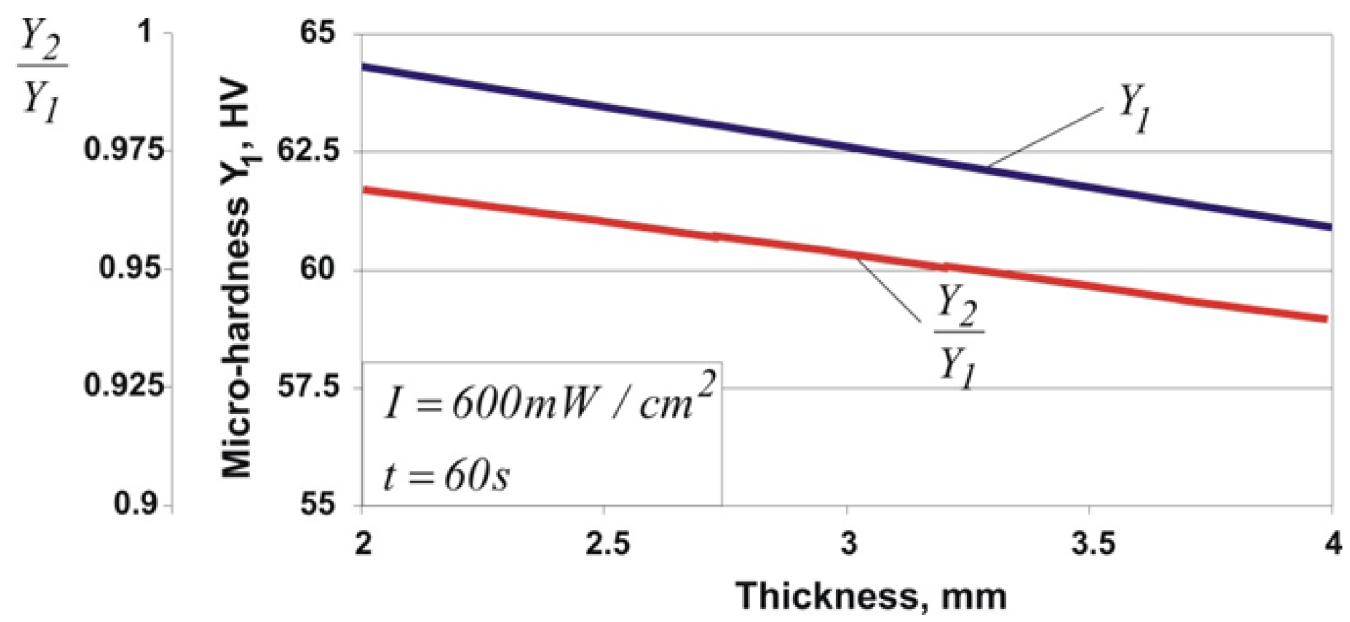

Figure 1. Dependences of the hardness on top surface $Y_{1}$ and the bottom/top hardness ratio $Y_{1} / Y_{2}$ as a function of thickness of $\mathrm{BC}$.

The graphs in Figure 2 show the dependence of the microhardness $Y_{1}$ on the top surface on the intensity, irradiation time and thickness. It can be clearly seen that for the three thicknesses $(2,3$ and $4 \mathrm{~mm})$ the increase of the irradiation time over $40 \mathrm{~s}$ is practically unnecessary, as the microhardness on the top surface increases insignificantly. Using Figure 2 and according to the specific conditions, an optimal combination of photopolymerization parameters can be selected to ensure the minimum allowable hardness of $61 \mathrm{HV}$.

The parameters of photopolymerization of BC Filtek One Bulk Fill Restorative are summarized in Table 5. These parameters provide the minimum allowable hardness $61 \mathrm{HV}$ on the top surface and hardness on the bottom surface- $80 \%$ of that of the top for layer thickness between 2-4 $\mathrm{mm}$. For comparison, the manufacturer recommends the irradiation time for $4 \mathrm{~mm}$ layer to be $40 \mathrm{~s}$ with intensity in the range $550-1000 \mathrm{~mW} / \mathrm{cm}^{2}$ and $20 \mathrm{~s}$ with intensity above $1000 \mathrm{~mW} / \mathrm{cm}^{2}$ [40,41]. The results of our study show that a satisfactory microhardness cannot be obtained by polymerization for $40 \mathrm{~s}$ with intensity of $550-700 \mathrm{~mW} / \mathrm{cm}^{2}$ and for $20 \mathrm{~s}$ with an intensity of $1000-1250 \mathrm{~mW} / \mathrm{cm}^{2}$.

Table 5. Optimal parameters of photopolymerization of BC Filtek One Bulk Fill Restorative.

\begin{tabular}{cccc}
\hline No & $\begin{array}{c}\text { Intensity, } \\
\mathbf{m W} / \mathbf{c m}^{\mathbf{2}}\end{array}$ & $\begin{array}{c}\text { Time, } \\
\text { s }\end{array}$ & $\begin{array}{c}\text { Layer Thickness, } \\
\text { mm }\end{array}$ \\
\hline 1 & $\mathrm{I}>1000$ & 20 & 2 \\
2 & $600-1500$ & 40 & 2 \\
3 & $\mathrm{I}>1000$ & 20 & 3 \\
4 & $600-1500$ & 40 & 3 \\
5 & $\mathrm{I}>1250$ & 20 & 4 \\
6 & $700-1250$ & 40 & 4 \\
7 & $\mathrm{I}<700$ & 60 & 4 \\
\hline
\end{tabular}



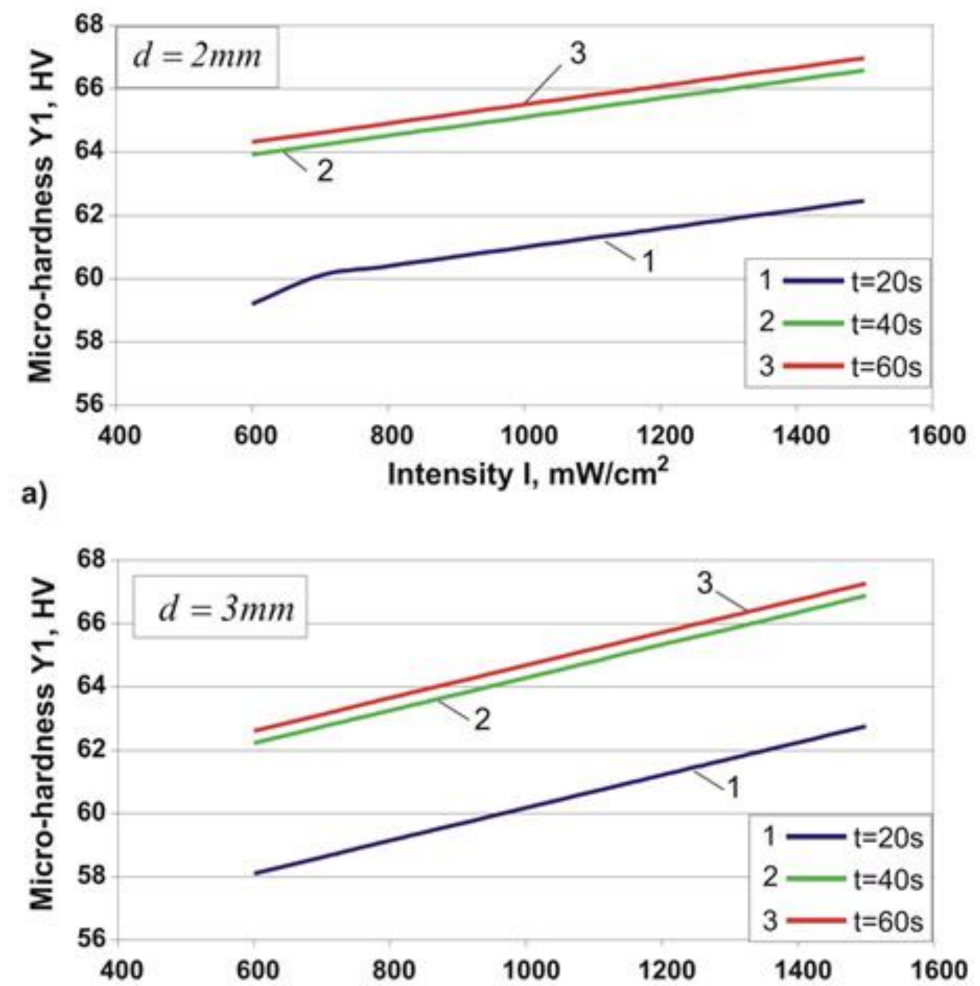

b)

Intensity $\mathrm{I}, \mathrm{mW} / \mathrm{cm}^{2}$

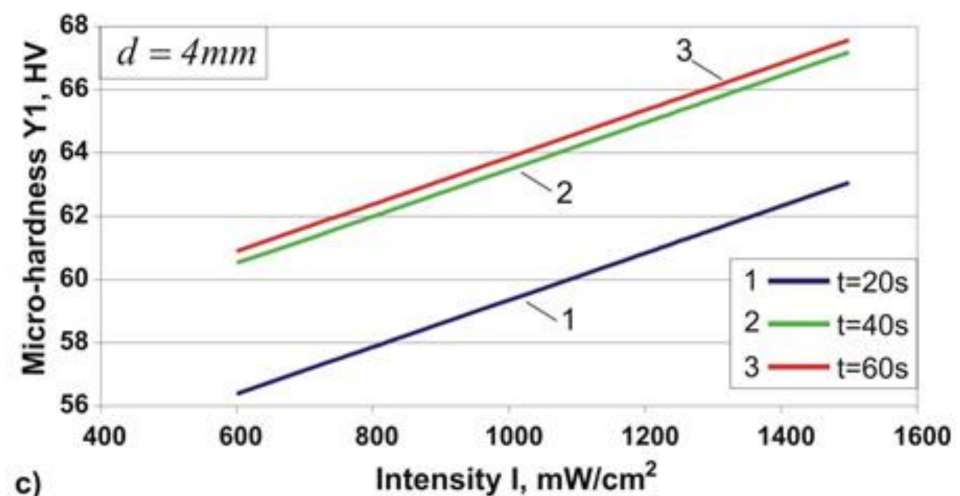

Figure 2. Dependence of the hardness on top surface on the intensity, irradiation time and layer thickness of: (a) $2 \mathrm{~mm}$; (b) $3 \mathrm{~mm}$ and (c) $4 \mathrm{~mm}$.

\subsection{Universal Nanofilled Flowable Composite G-Aenial Universal Flo}

The regression models for the objective functions Y1 and Y2 of FC G-aenial Universal Flo have the following form:

$$
\begin{gathered}
Y_{1}=46.762+1.715 x_{1}+1.054 x_{2}-1.326 x_{3}-0.766 x_{1} x_{3}+0.730 x_{1} x_{2} x_{3} \\
Y_{2}=37.091+4.214 x_{1}+5.271 x_{2}-7.769 x_{3}+1.994 x_{1} x_{3}+3.185 x_{2} x_{3}
\end{gathered}
$$

They are used to constitute Equation (5) from which the thickness $x_{3}$ is expressed:

$$
x_{3}=\frac{-0.3186+2.842 x_{1}+4.4278 x_{2}}{6.7082-2.6068 x_{1}-3.185 x_{2}+0.584 x_{1} x_{2}} .
$$

The calculated parameters of photopolymerization for the investigated composite are shown in Table A3 (Appendix C). The data analysis shows that all light curing regimes satisfy the requirement for the surface microhardness. It is noteworthy that two modes lead to lowest hardness on the top surface: regime 1, which is characterized by the lowest 
parameters intensity and time, and regime 2 with the highest parameters. The other combinations of parameters provide HVmax in the range 44.46-47.50 HV.

The most probable reason for the reduced surface microhardness at high values of the irradiation time is the large layer thickness $\left(7.63 \mathrm{~mm}\right.$ at $1500 \mathrm{~mW} / \mathrm{cm}^{2}$ and $5.37 \mathrm{~mm}$ at $1300 \mathrm{~mW} / \mathrm{cm}^{2}$ ). In these two cases, the volume of the composite to be polymerized is too large and the photopolymerization process cannot proceed completely even at $60 \mathrm{~s}$ of irradiation. Therefore in order to ensure maximum microhardness 46-48 HV on the top surface, when working with FC G-aenial Universal Flo the thickness of the layer should not exceed $5 \mathrm{~mm}$.

According to the recommendations of the manufacturer, $1.5 \mathrm{~mm}$ layer should be cured for $20 \mathrm{~s}$ with LCU intensity of $700 \mathrm{~mW} / \mathrm{cm}^{2}$ and for $10 \mathrm{~s}$ with intensity of $1200 \mathrm{~mW} / \mathrm{cm}^{2}$ [42]. The results of our study confirm that if these guidelines are followed, a satisfactory hardness or degree of polymerization of FC G-aenial Universal Flo could be obtained.

\section{Discussion}

The microhardness of resin-based composites depends mostly on the type and amount of the fillers, as well as the ratio of the monomer-polymer conversion $[3,5,23,26]$. The fillers of FC G-aenial Universal Flo consists of nano-powders of silicon dioxide and strontium glass with matrix/fillers ratio 31/69 wt\% (Table 1). Compared to the other two composites, FC has the lowest filler amount, which defines its lowest hardness. The matrix/filler ratio of BC Filtek One Bulk Fill Restorative is $23.5 / 76.5 \mathrm{wt} \%$, while that of UC Evetric is $19-20 / 80-81 \mathrm{wt} \%$. As it can be seen in Table 1, the filler amount of BC is lower than the UC, but its composition is different. The fillers of BC consist only of materials with high hardness: ceramic, silicon dioxide and zirconium particles. While in the composition of the UC fillers in addition to the Ba glass particles, ytterbium fluoride and mixed oxides, prepolimers with lower hardness are included. Therefore, the comparatively high filler content and its composition define the highest hardness of BC Filtek One Bulk Fill Restorative composite.

The conducted optimization shows that for UC Evetric (Table A1, Appendix A) not all light curing modes provide the required microhardness on the top surface. Hence, in this case it is not recommended to use LCUs, operating with intensity below $800 \mathrm{~mW} / \mathrm{cm}^{2}$. In the case of LCU with intensity of $800 \mathrm{~mW} / \mathrm{cm}^{2}$, the required microhardness on the top surface is guaranteed only at irradiation of $60 \mathrm{~s}$. When using LCUs with an intensity in the range of $1000-1500 \mathrm{~mW} / \mathrm{cm}^{2}$, it is possible to work with all irradiation times. It should be taken into account that as the duration of irradiation increases, the thickness of the composite layer and the hardness increase. When the maximum values of intensity and time $\left(1500 \mathrm{~mW} / \mathrm{cm}^{2}\right.$ and $\left.60 \mathrm{~s}\right)$ are used, a layer with thickness of $3 \mathrm{~mm}$ having $60 \mathrm{HV}$ microhardness on the top surface, can be successfully polymerized. The recommended light curing regimes of UC Evetric are marked with * in Table A1 (Appendix A).

The situation with BC Filtek One Bulk Fill Restorative is quite different. This composite is intended for posterior restorations [40], and therefore it is characterized by high hardness after polymerization and the ability to be applied in one layer in deep cavities. In our study, we investigated the composite layer thicknesses in the range of 2-4 mm. Regression analysis carried out ensures the accuracy of the results only in this range, i.e., where the bottom/top microhardness ratio is 0.8. According to the results shown in Table A2 (Appendix B), in regimes between mode $2\left(600 \mathrm{~mW} / \mathrm{cm}^{2}\right.$ and $\left.40 \mathrm{~s}\right)$ and mode $12\left(1000 \mathrm{~mW} / \mathrm{cm}^{2}\right.$ and $\left.60 \mathrm{~s}\right)$ this ratio is equal to or greater than 0.8 , and for regimes above mode 12 -the ratio is less than 0.8 . This means that the modes up to 12th provide a microhardness on the bottom surface higher than $80 \%$ of that on the top surface, but the hardness on the top surface is below the minimum allowable $61 \mathrm{HV}$ with the exception of mode $11\left(1000 \mathrm{~mW} / \mathrm{cm}^{2}\right.$ and $40 \mathrm{~s}$ ). In the modes above 12th, the hardness on the bottom surface is within $0.66-0.78$ $(66-78 \%)$ of the hardness on the top surface, which is below the required minimum of $80 \%$ [24-26]. The graphs in Figure 2 show that increasing the time above $40 \mathrm{~s}$ does not lead to a significant increase in the microhardness of the top surface, therefore in the 
photopolymerization of BC Filtek One Bulk Fill Restorative it is not necessary to irradiate the obturation for $60 \mathrm{~s}$. Modes that include intensities in the range $1000-1500 \mathrm{~mW} / \mathrm{cm}^{2}$ and irradiation times of 20 and $40 \mathrm{~s}$ guarantee microhardness above the minimum allowable for layer thicknesses of 4.71-12.07 $\mathrm{mm}$, but with bottom/top microhardness ratio less than 0.8. Taking into account that a tooth cavity with $7 \mathrm{~mm}$ depth is a rare case, and then modes in which the layer thickness is above this value are excluded. The recommended regimes for photopolymerization of BC Filtek One Bulk Fill Restorative are marked with * in Table A2 (Appendix B). The layer thickness, greater than the upper limit of the range and the bottom/top microhardness ratio less than 0.8 , are achieved in these curing regimes. In these cases, in order to ensure a higher microhardness on the bottom surface ( $\geq 80 \% \mathrm{HVmax})$, it is necessary to work with a layer thickness less than that indicated in Table A2 (Appendix B). When working with a layer thickness in the range of $2-4 \mathrm{~mm}$, the photopolymerization modes can be selected from Table 5 .

Regarding FC G-aenial Universal Flo, it is found that all light curing regimes used in the study, provide the required microhardness on the top surface, but to ensure its maximum value of 46-48 HV, the layer thickness should not exceed $5 \mathrm{~mm}$. Therefore, all modes in Table A3 (Appendix C) can be recommended for successful photopolymerization.

The results of the present study have shown that the instructions for light curing only of the manufacturer of FC G-aenial Universal Flo guarantee the required microhardness of the filling. The recommendations for work with the other two composites, UC Evetric and BC Filtek One Bulk Fill Restorative, do not meet the requirement for high microhardness, which means that a sufficient degree of polymerization can not be achieved. The recommended photopolymerization regimes for the three types of composites, developed in this study, guarantee high microhardness of the fillings.

\section{Conclusions}

In this study, optimization of the parameters of photopolymerization process of dental composites from three different groups was conducted using regression analysis. To the best of our knowledge, an engineering approach is applied here for the first time in investigation of resin-based composites. For all composites, regression models for the microhardness on the top and bottom surfaces of the composite layer were established. Both the layer thickness and the microhardness on the samples top and bottom surfaces of each composite were calculated for 21 modes of photopolymerization varying with the light intensity and irradiation time. It was established that photopolymerization guidelines only of FC manufacturer guarantee the required hardness, while recommended regimes for UC and BC do not satisfy this requirement. Tables, containing recommended light curing regimes, were developed for three composite types, guaranteeing high hardness of composite restoration. They were designed to facilitate work of dentists in dental offices.

Author Contributions: Conceptualization, T.D. and J.M.; methodology, J.M. and T.D.; software, J.M.; experiment, G.G. and V.T.; data analysis, T.D. and J.M.; writing-original draft preparation, T.D., G.G. and J.M.; writing-review and editing, J.M.; visualization, J.M.; supervision, T.D. and J.M.; project administration, V.P. All authors have read and agreed to the published version of the manuscript.

Funding: This research received no external funding.

Institutional Review Board Statement: Not applicable.

Informed Consent Statement: Not applicable.

Conflicts of Interest: The authors declare no conflict of interest. 


\section{Appendix A}

Table A1. Parameters of photopolymerization of UC Evetric.

\begin{tabular}{|c|c|c|c|c|c|}
\hline \multirow{2}{*}{ № } & \multirow{2}{*}{$\begin{array}{l}\text { Intensity, } \\
\mathrm{mW} / \mathrm{cm}^{2}\end{array}$} & \multirow{2}{*}{$\begin{array}{l}\text { Time, } \\
\text { s }\end{array}$} & \multirow{2}{*}{$\begin{array}{l}\text { Layer Thickness, } \\
\text { mm }\end{array}$} & \multicolumn{2}{|c|}{ Hardness, HV } \\
\hline & & & & Top & Bottom \\
\hline 1 & 600 & 20 & 2.09 & 42.05 & 33.64 \\
\hline 2 & 600 & 40 & 2.33 & 44.07 & 35.26 \\
\hline 3 & 600 & 60 & 2.81 & 46.56 & 37.25 \\
\hline 4 & 700 & 20 & 1.97 & 45.00 & 36.00 \\
\hline 5 & 700 & 40 & 2.19 & 46.97 & 37.58 \\
\hline 6 & 700 & 60 & 2.62 & 49.36 & 39.48 \\
\hline 7 & 800 & 20 & 1.88 & 47.57 & 38.05 \\
\hline 8 & 800 & 40 & 2.08 & 49.49 & 39.59 \\
\hline $9 *$ & 800 & 60 & 2.46 & 51.80 & 41.44 \\
\hline 10 * & 1000 & 20 & 1.78 & 51.53 & 41.22 \\
\hline 11 * & 1000 & 40 & 2.95 & 53.40 & 42.72 \\
\hline 12 * & 1000 & 60 & 2.31 & 55.64 & 44.51 \\
\hline 13 * & 1200 & 20 & 1.76 & 53.96 & 43.17 \\
\hline $14 *$ & 1200 & 40 & 1.98 & 55.86 & 44.69 \\
\hline $15 *$ & 1200 & 60 & 2.39 & 58.21 & 46.57 \\
\hline $16^{*}$ & 1300 & 20 & 1.85 & 54.61 & 43.69 \\
\hline 17 * & 1300 & 40 & 2.06 & 56.57 & 45.26 \\
\hline 18 * & 1300 & 60 & 2.54 & 59.07 & 47.26 \\
\hline 19 * & 1500 & 20 & 2.07 & 54.82 & 43.85 \\
\hline $20 *$ & 1500 & 40 & 2.39 & 56.98 & 45.59 \\
\hline 21 * & 1500 & 60 & 3.17 & 60.08 & 48.06 \\
\hline
\end{tabular}

Note: *-recommended regimes for successful photopolymerization.

\section{Appendix B}

Table A2. Parameters of photopolymerization of BC Filtek One Bulk Fill Restorative.

\begin{tabular}{|c|c|c|c|c|c|c|}
\hline \multirow{2}{*}{ № } & \multirow{2}{*}{$\begin{array}{l}\text { Intensity, } \\
\mathrm{mW} / \mathrm{cm}^{2}\end{array}$} & \multirow{2}{*}{$\begin{array}{c}\text { Time, } \\
\text { s }\end{array}$} & \multirow{2}{*}{$\begin{array}{l}\text { Layer Thickness, } \\
\text { mm }\end{array}$} & \multicolumn{2}{|c|}{ Hardness, HV } & \multirow{2}{*}{$Y_{2} / Y_{1}$} \\
\hline & & & & Top, $Y_{1}$ & Bottom, $Y_{2}$ & \\
\hline 1 & 600 & 20 & 3.86 & 56.63 & 45.30 & 0.80 \\
\hline 2 & 600 & 40 & 4.72 & 59.29 & 48.81 & 0.82 \\
\hline 3 & 600 & 60 & 8.36 & 53.47 & 46.27 & 0.86 \\
\hline 4 & 700 & 20 & 4.03 & 57.08 & 46.94 & 0.82 \\
\hline 5 & 700 & 40 & 4.99 & 59.78 & 49.07 & 0.82 \\
\hline 6 & 700 & 60 & 9.30 & 53.78 & 46.33 & 0.86 \\
\hline 7 & 800 & 20 & 4.23 & 57.58 & 47.06 & 0.82 \\
\hline $8 *$ & 800 & 40 & 5.31 & 60.35 & 49.31 & 0.82 \\
\hline 9 & 800 & 60 & 10.58 & 54.08 & 46.20 & 0.85 \\
\hline 10 & 1000 & 20 & 4.71 & 58.78 & 47.26 & 0.80 \\
\hline 11 * & 1000 & 40 & 6.16 & 61.72 & 49.66 & 0.80 \\
\hline 12 & 1000 & 60 & 15.35 & 54.61 & 44.70 & 0.82 \\
\hline 13 * & 1200 & 20 & 5.34 & 60.34 & 47.38 & 0.78 \\
\hline $14^{*}$ & 1200 & 40 & 7.50 & 63.66 & 49.73 & 0.78 \\
\hline 15 & 1200 & 60 & 32.66 & 54.75 & 36.13 & 0.66 \\
\hline 16 * & 1300 & 20 & 5.73 & 61.32 & 47.39 & 0.77 \\
\hline 17 & 1300 & 40 & 8.51 & 65.03 & 49.57 & 0.76 \\
\hline 18 & 1300 & 60 & 91.26 & 53.28 & \multicolumn{2}{|c|}{$\begin{array}{c}\text { The results have no } \\
\text { physical sense }\end{array}$} \\
\hline 19 * & 1500 & 20 & 6.79 & 63.89 & 47.27 & 0.74 \\
\hline 20 & 1500 & 40 & 12.07 & 69.59 & 48.39 & 0.70 \\
\hline 21 & 1500 & 60 & \multicolumn{4}{|c|}{ The results have no physical sense } \\
\hline
\end{tabular}




\section{Appendix C}

Table A3. Parameters of photopolymerization of FC G-aenial Universal Flo.

\begin{tabular}{|c|c|c|c|c|c|}
\hline \multirow{2}{*}{ № } & \multirow{2}{*}{$\begin{array}{l}\text { Intensity, } \\
\mathrm{mW} / \mathrm{cm}^{2}\end{array}$} & \multirow{2}{*}{$\begin{array}{l}\text { Time, } \\
\text { s }\end{array}$} & \multirow{2}{*}{$\begin{array}{l}\text { Layer Thickness, } \\
\text { mm }\end{array}$} & \multicolumn{2}{|c|}{ Hardness, HV } \\
\hline & & & & Top & Bottom \\
\hline 1 & 600 & 20 & 2.42 & 43.89 & 35.11 \\
\hline 2 & 600 & 40 & 2.66 & 45.24 & 36.19 \\
\hline 3 & 600 & 60 & 3.23 & 45.81 & 36.65 \\
\hline 4 & 700 & 20 & 2.44 & 44.46 & 35.57 \\
\hline 5 & 700 & 40 & 2.71 & 45.64 & 36.51 \\
\hline 6 & 700 & 60 & 3.37 & 46.00 & 36.80 \\
\hline 7 & 800 & 20 & 2.46 & 45.02 & 36.02 \\
\hline 8 & 800 & 40 & 2.77 & 46.02 & 36.82 \\
\hline 9 & 800 & 60 & 3.54 & 46.15 & 36.92 \\
\hline 10 & 1000 & 20 & 2.51 & 46.09 & 36.87 \\
\hline 11 & 1000 & 40 & 2.91 & 46.68 & 37.35 \\
\hline 12 & 1000 & 60 & 4.01 & 46.29 & 37.03 \\
\hline 13 & 1200 & 20 & 2.57 & 47.06 & 37.65 \\
\hline 14 & 1200 & 40 & 3.11 & 47.16 & 37.73 \\
\hline 15 & 1200 & 60 & 4.77 & 46.01 & 36.81 \\
\hline 16 & 1300 & 20 & 2.61 & 47.50 & 38.00 \\
\hline 17 & 1300 & 40 & 3.24 & 47.29 & 37.84 \\
\hline 18 & 1300 & 60 & 5.37 & 45.58 & 36.46 \\
\hline 19 & 1500 & 20 & 2.72 & 48.22 & 38.58 \\
\hline 20 & 1500 & 40 & 3.61 & 47.19 & 37.75 \\
\hline 21 & 1500 & 60 & 7.63 & 43.22 & 34.58 \\
\hline
\end{tabular}

\section{References}

1. Georgiev, G.; Panov, V.; Dikova, T. Investigation of light intensity of wireless LED light curing units. J. Technol. Univ. Gabrovo 2020, $60,40-45$.

2. Sensi, L.G.; Strassler, H.E.; Webley, W. Direct Composite Resins. Inside Dent. 2007, 3, 76.

3. Anusavice, K.J.; Shen, C.; Rawls, H.R. Phillips' Science of Dental Materials; Elsevier Saunders: St. Louis, MO, USA, 2012 ; pp. $291-293$.

4. Van Noort, R.; Barbour, R. Introduction to Dental Materials-E-Book; Elsevier Mosby: Edinburgh, UK, 2013; pp. 73-95.

5. Dikova, T. Dental Materials Science: Lectures and Laboratory Classes Notes Part II; MU-Varna: Varna, Bulgaria, $2014 ;$ p. 150.

6. Dikova, T.; Milkov, M. Nanomaterials in dental medicine. In Proceedings of the 10th Workshops "Nanoscience \& Nanotechnology", Sofia, Bulgaria, 4-9 November 2009; Balabanova, E., Dragieva, I., Eds.; BAS-NCCNT: Sofia, Bulgaria, 2009 ; pp. $203-209$.

7. Dikova, T.; Abadzhiev, M. Clinical application of the contemporary nano-materials (part 1-laboratory composites). J. IMAB 2009, 15, 67-70.

8. Mitra, S.B.; Wu, D.; Holmes, B.N. An application of nanotechnology in advanced dental materials. J. Am. Dent. Assoc 2003, 134, 1382-1390. [CrossRef]

9. Olmez, A.; Oztas, N.; Bodur, H. The effect of flowable resin composite on microleakage and internal voids in class II composite restorations. Oper. Dent. 2004, 29,713-719. [PubMed]

10. Yacizi, A.R.; Ozgunaltay, G.; Dayangac, B. The effect of different types of flowable restorative resins on microleakage of Class V cavities. Oper. Dent. 2003, 28, 773-778.

11. Scotti, N.; Comba, A.; Gambino, A.; Manzon, E.; Breschi, L.; Paolino, D.; Pasqualini, D.; Berutti, E. Influence of operator experience on non-carious cervical lesion restorations: Clinical evaluation with different adhesive systems. Am. J. Dent. 2016, 29, 33-38.

12. Miletic, V.; Pongprueksa, P.; De Munck, J.; Brooks, N.R.; Van Meerbeek, B. Curing characteristics of flowable and sculptable bulk-fill composites. Clin. Oral Investig. 2017, 21, 1201-1212. [CrossRef] [PubMed]

13. Son, S.A.; Park, J.K.; Seo, D.G.; Ko, C.C.; Kwon, Y.H. How light attenuation and filler content affect the microhardness and polymerization shrinkage and translucency of bulk-fill composites? Clin. Oral Investig. 2017, 21, 559-565. [CrossRef]

14. Van Ende, A.; Lise, D.P.; De Munck, J.; Vanhulst, J.; Wevers, M.; Van Meerbeek, B. Strain development in bulk-filled cavities of different depths characterized using a non-destructive acoustic emission approach. Dent. Mater. 2007, 33, e165-e177. [CrossRef] [PubMed]

15. Fronza, B.M.; Rueggeberg, F.A.; Braga, R.R.; Mogilevych, B.; Soares, L.E.S.; Martin, A.A.; Giannini, M. Monomer conversion, microhardness, internal marginal adaptation, and shrinkage stress of bulk-fill resin composites. Dent. Mater. 2015, 31, 1542-1551. [CrossRef] [PubMed]

16. Rosatto, C.M.P.; Bicalho, A.A.; Veríssimo, C.; Bragança, G.F.; Rodrigues, M.P.; Tantbirojn, D.; Soares, C.J. Mechanical properties, shrinkage stress, cuspal strain and fracture resistance of molars restored with bulk-fill composites and incremental filling technique. J. Dent. 2015, 43, 1519-1528. [CrossRef] [PubMed]

17. Tomaszewska, I.M.; Kearns, J.O.; Ilie, N.; Fleming, G.J. Bulk fill restoratives: To cap or not to cap-That is the question? J. Dent. 2015, 43, 309-316. [CrossRef] [PubMed] 
18. Lucey, S.; Lynch, C.D.; Ray, N.J.; Burke, F.M.; Hannigan, A. Effect of pre-heating on the viscosity and microhardness of a resin composite. J. Oral Rehab. 2010, 37, 278-282. [CrossRef]

19. Poggio, C.; Lombardini, M.; Gaviati, S.; Chiesa, M. Evaluation of Vickers hardness and depth of cure of six composite resins photo-activated with different polymerization modes. J. Conserv. Dent. 2012, 15, 237. [CrossRef] [PubMed]

20. Torres, C.R.; Caneppele, T.M.; Borges, A.B.; Torres, A.; Araújo, M.A. Influence of pre-cure temperature on Vickers microhardness of resin composite. Int. J. Contemp. Dent. 2011, 2, 41-45.

21. Saade, E.G.; Bandeca, M.C.; Rastelli, A.N.D.S.; Bagnato, V.S.; Porto-Neto, S.T. Influence of pre-heat treatment and different light-curing units on Vickers hardness of a microhybrid composite resin. Laser Phys. 2009, 19, 1276-1281. [CrossRef]

22. Osternack, F.H.R.; Caldas, D.B.D.M.; Rached, R.N.; Vieira, S.; Platt, J.A.; Almeida, J.B.D. Impact of refrigeration on the surface hardness of hybrid and microfilled composite resins. Braz. Dent. J. 2009, 20, 42-47. [CrossRef]

23. Fennis, W.M.; Ray, N.J.; Creugers, N.H.; Kreulen, C.M. Microhardness of resin composite materials light-cured through fiber reinforced composite. Dent. Mater. 2009, 25, 947-951. [CrossRef]

24. Price, R.B.; Felix, C.A.; Andreou, P. Evaluation of a second-generation LED curing light. J. Can. Dent. Assoc. 2003, 69, 666.

25. Yap, A.U.; Wong, N.Y.; Siow, K.S. Composite cure and shrinkage associated with high intensity curing light. Oper. Dent. 2003, 28, 357-364.

26. Bouschlicher, M.R.; Rueggeberg, F.A.; Wilson, B.M. Correlation of bottom-to-top surface microhardness and conversion ratios for a variety of resin composite compositions. Oper. Dent. 2004, 29, 698-704.

27. Zhu, S.; Platt, J. Curing efficiency of three different curing modes at different distances for four composites. Oper. Dent. 2011, 36, 362-371. [CrossRef]

28. Aguiark, F.H.; Braceiro, A.; Lima, D.A.N.L.; Ambrosano, G.M.B.; Lovadino, J.R. Effect of Light Curing Modes and Light Curing Time on the Microhardness of a Hybrid Composite Resin. J. Contemp. Dent. Pract. 2007, 8, 1-8.

29. Spajic, J.; Par, M.; Milat, O.; Demoli, N.; Bjelovucic, R.; Prskalo, K. Effects of curing modes on the microhardness of resin-modified glass ionomer cements. Acta Stomatol. Croat. 2019, 53, 37. [CrossRef] [PubMed]

30. Alkhudhairy, F.I. The effect of curing intensity on mechanical properties of different bulk-fill composite resins. Clin. Cosmet. Investig. Dent. 2017, 9, 1. [CrossRef] [PubMed]

31. Santini, A.; Turner, S. General dental practitioners' knowledge of polymerisation of resin-based composite restorations and light curing unit technology. Br. Dent. J. 2011, 211, E13. [CrossRef] [PubMed]

32. Georgiev, G.P. Factors associated with light curing units: A questionnaire survey. Scr. Sci. Med. Dent. 2019, 5, 37-43. [CrossRef]

33. Dikova, T.D.; Kulinich, S.A.; Iwamori, S.; Yamaguchi, S. Technological parameters optimization in picosecond laser texturing of titanium surfaces. J. Phys. Conf. Ser. 2021, 1859, 012037. [CrossRef]

34. Maximov, J.T.; Duncheva, G.V.; Anhev, A.P.; Dunchev, V.P.; Capec, J. A cost-effective optimization approach for improving the fatigue strength of diamond-burnished steel components. J. Braz. Soc. Mech. Sci. Eng. 2021, 43, 1-13. [CrossRef]

35. Maximov, J.T.; Duncheva, G.V.; Anchev, A.P.; Dunchev, V.P. Smoothing, deep or mixed diamond burnishing of low-alloy steel components-Optimization procedures. Int. J. Adv. Manuf. Technol. 2020, 106, 1917-1929. [CrossRef]

36. Malakov, I.; Zaharinov, V.; Tzenov, V. Size ranges optimization. Procedia Eng. 2015, 100, 791-800. [CrossRef]

37. Malakov, I.; Zaharinov, V. Computer Aided Determination of Criteria Priority for Structural Optimization of Technical Systems. Procedia Eng. 2014, 69, 735-744. [CrossRef]

38. Objelean, A.C.; Silaghi-Dimitrescu, L.; Furtos, G.; Badea, M.A.; Moldovan, M. The influence of organic-inorganic phase mixures on degradation behavior of some resin composites used in conservative dentistry. J. Optoelectron. Adv. Mater. 2016, 18, 567-575.

39. Safety Data Sheet, Evetric; Ivoclar Vivadent AG: Schaan, Liechtenstein, 2015; 6p.

40. 3M Filtek One Bulk Fill Restorative, Technical Product Profile; 3m.com: St. Paul, MN, USA; Available online: https://multimedia.3m. $\mathrm{com} / \mathrm{mws} / \mathrm{media} / 1317671 \mathrm{O} / 3 \mathrm{~m}$-filtek-one-bulk-fill-restorative-technical-product-profile.pdf (accessed on 2 April 2021).

41. 3M Filtek One Bulk Fill Restorative, Safety Data Sheet; 3m.com: St. Paul, MN, USA, 31 July 2020; Available online: https: //multimedia.3m.com/mws/mediawebserver?mwsId=SSSSSuUn_zu8100xm82Bm8_ZPv70k17zHvu91xtD7SSSSSS-- (accessed on 2 April 2021).

42. G-Aenial Universal Flo, Technical Manual; GC: Leuven, Belgium; 20p, Available online: www.gceurope.com; https://cdn.gceurope. com/v1/PID/gaenialuniversalflo/manual/MAN_G-aenial_Universal_Flo_Technical_Manual_en.pdf; (accessed on 2 April 2021).

43. Yilmaz, E.Ç.; Sadeler, R.; Oner, V.; Yeşilyurt, M. Investigation of mechancal properties of restorative composites after artificial aging. In Proceedings of the International Energy and Engineering Congress, UEMK 2016 Conference Proceedings, Gaziantep University, Gaziantep, Turkey, 13-14 October 2016; pp. 739-743. 